result of intensive clearance and cultivation of upland areas and because of the spread of exotic plant species introduced by man (see Nature, 242, 299; 1973). Davies (Nature, 249, 788; 1974) pointed out the threat to the islands' flora presented by feral goats and the problems in carrying out scientific research and conservation on the inadequate budget of the Charles Darwin Research Station. Can one be sure that the demise of the Galapagos flora and fauna will even be recorded adequately?

A research programme to monitor habitat changes in the islands was instigated by the research station in 1966. Permanent plots of between $6.25 \mathrm{~m}^{2}$ and $100 \mathrm{~m}^{2}$ were established on several islands in habitats which were thought to be threatened, and recordings have been made since that time of vegetational changes within the plots. Hamann (Biol. Cons., 7, 37; 1975) has now presented some of the data emerging from this study over the period 1966-73.

The arid zone vegetation has suffered to different degrees on the various islands. On Pinta, where goats have in the past been a most serious pest, the denudation of vegetation has been severe, sometimes resulting in soil erosion. Recent reduction in goat population density has not yet resulted in any marked recovery of the vegetation. There is however cause for optimism in view of the regeneration which has been noted on Santa Fé, where feral goats were exterminated in 1971. Cordia lutea, Encelia hispida. Lantana peduncularis and Scalesia helleri are all recovering in the arid zone of this island since the cessation of grazing. One might hope that regeneration will occur in Pinta also, if goat populations can be further reduced.

The Scalesia pedunculata forests of Isla Santa Cruz, although badly affected by grazing and clearance, seem to have the capacity for rapid recovery and growth under suitable conditions. Recent intensive hunting of introduced mammals by National Park wardens may be responsible for the observed increase in saplings of Scalesia within the plots. However, cattle seem to be very partial to young Scalesia trees, so full recovery can only occur if cattle grazing is controlled. Exclosure plots could supply the answer to this.

Perhaps the most sensitive vegetation type of the Galapagos is that dominated by Miconia robinsoniana with Cyathea weatherbyana. Much of this zone has been damaged by burning, followed by cattle grazing, and this has resulted in its replacement by ferns, particularly Pteridium aquilinum. It may be that recent prolonged droughts have also contributed to the failure of regeneration in Miconia. This vegetation type will undoubtedly provide the most difficult conservation problem of all on the Galapagos. It has almost disappeared from San Cristóbal and is failing to recover on Santa Cruz, its only other station. Protection of the zone from further burning and grazing must be regarded as a management priority.

The control of introduced mammals on the Galapagos has proved possible and worthwhile. It is to be hoped that funds will be found to continue and intensify this programme of conservation and that schemes can be initiated which will satisfy the needs of both farmer and conservationist on the islands.

\section{Long period of lunar crater formation}

\section{from Peter J. Smith}

ONE of the hopes not entirely fulfilled by the Apollo missions was that it would be possible to recover a significant number of lunar rocks older than 4,000 million years. As terrestrial rocks of corresponding age have never been found, some workers had hoped that access to lunar material would enable important light to be thrown on the first 500-600 million years' evolution not only of the Moon itself but also of the Solar System and particularly the Earth. Unfortunately, most lunar mare and highland basalts dated radiometrically appear to be between 3,950 and 3,130 million years old. It is true that some highland rocks, notably the cataclastic anorthosites, have yielded ages much closer to that of the Solar System; but some doubt has been expressed as to what such great rock ages really mean. The difficulty is that much of the lunar regolith in the appropriate regions represents ejecta from the major basins, material which has been severely shocked; and it is not entirely clear just how shock affects a rock's radioactive properties.

Recently, however, Gooley et al. (Geochim. Cosmochim. Acta, 38, 1329; 1974) described an unshocked troctolite (Apollo 17) comprising plagioclase, olivine and bronzite, which they conclude cooled at a rate of a few tens of degrees per million years at a depth of 10-30 km. Two whole rock samples and a plagioclase separate from this material have now been dated by Husain and Schaeffer (Geophys. Res. Lett., 2, 29; 1975) using the ${ }^{40} \mathrm{Ar}-{ }^{39} \mathrm{Ar}$ technique. Extensive tests and close agreement between the ages obtained from all three samples convince Husain and Schaeffer that the accurate mean age of the troctolite is $4,260 \pm 20$ million years.

The corresponding ${ }^{38} \mathrm{Ar} / \mathrm{Ca}$ cosmic ray exposure age is $156 \pm 8 \mathrm{Myr}$, suggesting that the troctolite was last brought to the surface comparatively recently. The much older ${ }^{40} \mathrm{Ar}-{ }^{39} \mathrm{~A} i$ age, on the other hand, supports the major conclusion from Gooley and his colleagues that the rock was originally a product of large scale igneous processes which formed the early lunar crust. The combined evidence from petrography and the Ar systematics is that the troctolite probably formed about 4,500 million years ago and then cooled very slowly at depth for tens to hundreds of millions of years. During most of this phase the temperature was apparently sufficiently high to make the rock an open Ar system. But for the past 4,260 Myr the rock has evidently been a closed Ar system, thus enabling one to date the time at which it was excavated from depth and reburied under an ejecta blanket.

This is the simplest and most reasonable chronology consistent with the available data. But Husain and Schaeffer believe that they can go even further in relating the rock's inistory to named events on the Moon. For (shocked) lunar breccias from Apollos 14-17, the histogram of measured ${ }^{40} \mathrm{Ar}-{ }^{39} \mathrm{Ar}$ ages (see, for example, Schaeffer and Husain, Geochim. Cosmochim. Acta, Suppl. 4, 1847; 1973) covers the range $3,900-4,260$ million years and is sharply peaked at 3,9004,000 Myr. As the breccias were almost certainly formed by impacts on the lunar surface and as extensive Imbrium ejecta exist at the Apollo 14-17 landing sites, the histogram peak strongly supports the view that the Imbrium event occurred between 3,900 and 4,000 million years ago.

If this is so, the older breccias (assuming their measured ages to be reliable) and the Apollo 17 trocolite must be related to earlier events. As far as the trocolite is concerned, the impact which excavated it is now identified by Husain and Schaeffer as the Serenitatis event, largely because the Apollo 17 site lies at the rim of the Serenitatis basin. If this is correct, it follows that the age of the Serenitatis is probably 4,260 Myr, the age of the troctolite. This, in turn, suggests that what Husain and Schaeffer term the "lunar basin forming era" lasted at least $300 \mathrm{Myr}$ (Serenitatis-Imbrium). In fact it may have lasted much longer because the Serenitatis impact event was preceeded by the Fecunditatis, Tranquillitatis and Nubium events. In any case it now appears that these major lunar basins could not all have been formed in a relatively short time about 4,000 million years ago, as some workers have suggested. 